\title{
Coronavirus Infection in Rats
}

\author{
K. Nagashima ${ }^{1}$, H. Wege ${ }^{2}$, R. Meyermann ${ }^{3}$, and V. Ter Meulen ${ }^{2}$
}

\section{Summary}

Murine coronavirus JHM infection in rats can be accompanied by different types of demyelinating central nervous system (CNS) diseases. Infection of suckling rats results in an acute, disseminated encephalomyelitis affecting both neurons and oligodendroglia cells. After an average incubation period of 2-3 weeks, weanling rats develop a predominantly subacute demyelinating encephalomyelitis (SDE) characterized by perivascular cuffings, demyelinated foci, and destruction of oligodendroglia cells, leaving the neurons and axons intact. After 3-8 months, some of the weanling rats which do not after 3 weeks display any CNS affection develop a neurological disease with neuropathological changes similar to SDE. However, in addition to demyelination, remyelination is detectable in this disease pattern. Infectious coronavirus can be isolated from all diseased animals. The infection of weanling rats with coronavirus JHM offers the possibility to explore experimentally the pathogenetic mechanisms responsible for a virus-associated demyelinating process.

\section{Introduction}

Demyelinated lesions occur in several virus-induced CNS diseases of man and animals [12]. The etiologic agents have been identified for most of the diseases, but the pathogenetic mechanisms leading to the neurological changes are unknown. Therefore, a laboratory animal model using a virus for which a detailed knowledge of biochemistry and replication exists would be useful for the analysis of the virus-host relationship in demyelination. The murine coronavirus strain JHM meets these requirements. The essential structural features of the virion are known [14, 15], a persistent infection in tissue culture can be established $[6,10]$ and ts mutants are available which induce demyelination at high frequency [4]. In mice, JHM infection is accompanied by an acute disseminated encephalitis with a short incubation period and rapid death $[1,5,16]$. In weanling rats, however, JHM virus infection leads to a subacute demyelinating encephalomyelitis $[1,7,8]$. Based on this observation, the infection of weanling rats with JHM virus was further investigated. In the present communication the different diseases of rats occurring after JHM infections are described.

1 Present Address: Department of Pathology, Faculty of Medicine, University of Tokyo. 7-3-1 Hongo, Bunkyo-ku, Tokyo 113/Japan

2 Institut für Virologie und Immunobiologie, Universität Würzburg, Versbacher Str. 7, D-8700 Würzburg/FRG

3 Neuropathologisches Institut, Universität Göttingen, D-3400 Göttingen/FRG 


\section{Materials and Methods}

\section{Animals}

Suckling (3-7 days of age) and weanling (20-25 days of age) rats, strain CHBB/ THOM, were obtained specific-pathogen free from Thomae, Biberach, Germany.

\section{Virus}

JHM virus was passaged by intracerebral inoculation in suckling mice and rats and a $20 \%$ brain suspension was used for the inoculation of animals.

\section{Animal Inoculation}

Weanling and newborn rats were inoculated into the left brain hemisphere. The animals obtained approximately $5 \times 10^{4}$ TCID 50 of JHM virus.

\section{Virus Isolation}

After dissection under aseptic conditions, the specimens were washed in cold PBS with antibiotics and homogenized in a glass douncer to give a $15 \%(\mathrm{w} / \mathrm{v})$ suspension. The homogenates were absorbed for $1 \mathrm{~h}$ on monolayers of $\mathrm{Sac}(-)$ cells $(0.3 \mathrm{ml} /$ petridish $20 \mathrm{ccm}$ ), washed, and incubated with $5 \mathrm{ml}$ Eagle's minimal essential medium containing 5\% fetal calf serum. Cultures which did not show a CPE characteristic of JHM infection after $48 \mathrm{~h}$ were passaged. Sac(-) cells are a mouse moloneysarcoma line obtained from Dr. Mussgay, Bundesforschungsanstalt für Viruskrankheiten der Tiere, Tübingen, Germany.

\section{Immunofluorescence Studies}

Cryostate section ( $8 \mu$ thick) were fixed for $10 \mathrm{~min}$ in acetone and stained using the indirect immunofluorescence technique. Antiserum against JHM was prepared in mice. FITC-labeled anti-mouse immunoglobulin was obtained from Microbiological Associates, Maryland, USA. The sera were absorbed with brain powder from uninfected animals prior to use.

\section{Light and Electron Microscopy}

The animals were anesthetized with ether and perfused with a fixative consisting of $2 \%$ paraformaldehyde and $2.5 \%$ glutaraldehyde buffered to $\mathrm{pH}$ with phosphate. For both light and electron microscopy, coronal sections of brain, spinal cord, and optic 
nerve were made alternatively. The tissue for light microscopy was postfixed in $10 \%$ formalin and embedded in paraffin. The specimens were stained with hemytoxylin-eosin, the Klüver-Barrera method for myelin and the Glees-Marsland method for axons. Blocks for electron microscopy were postfixed in $1 \%$ osmium tetroxide buffered with phosphate, stained en bloc with $2.5 \%$ uranyl acetate, dehydrated, and embedded in epon. Thick sections $(1 \mu \mathrm{m})$ were taken from all regions sampled, stained with $1 \%$ toluidine blue, and examined by light microscopy. Thin sections of selected areas were cut with a Reichert OmU-3 ultramicrotome, placed on formvarcoated grids, and stained with lead citrate. The preparations were examined with a Zeiss 10B electron microscope.

\section{Results}

\section{JHM Infection in Suckling Rats}

Out of 78 animals infected, 57 became moribund with an incubation period of approximately one week. Neuropathological examinations revealed that the main lesions were situated in the cerebral cortex and brainstem. The lesions found in the brain were usually necrotic with polymorphonuclear leukocyte infiltrations. Neuronal necrosis, neurophagia, and glial nodules were frequently encountered. The lesions in the brainstem showed multiple large demyelinating plaques. Viral antigens were demonstrated by immunofluorescence both in neurons and glial cells. Electron-microscopic examination revealed intact virus particles in the neuronal and glial cytoplasm [7]: Infectious JHM virus was isolated from diseased animals.

\section{JHM Infection in Weanling Rats}

JHM inoculations into weanling rats were followed by neurological diseases which developed either 2-3 weeks or 3-8 months after virus inoculation (Table 1). The clinical signs consisted of hindleg paralysis or spastic tetraplegia and seizures lasting up to 1 week. Both groups of animals were neuropathologically examined, and our observations are described in the following sections.

\section{Subacute Demyelinating Encephalomyelitis (SDE)}

Those weanling rats which 2-3 weeks after inoculation developed a neurological disease revealed neuropathological lesions mainly located in the brainstem, the optic

Table 1. Coronavirus JHM infection in weanling rats

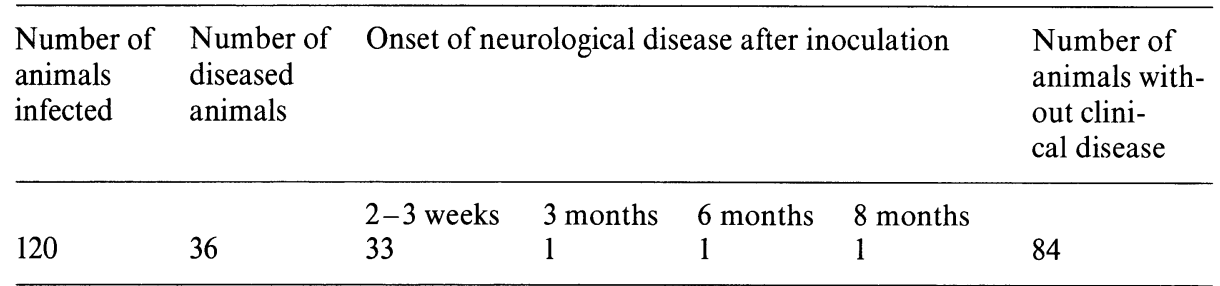



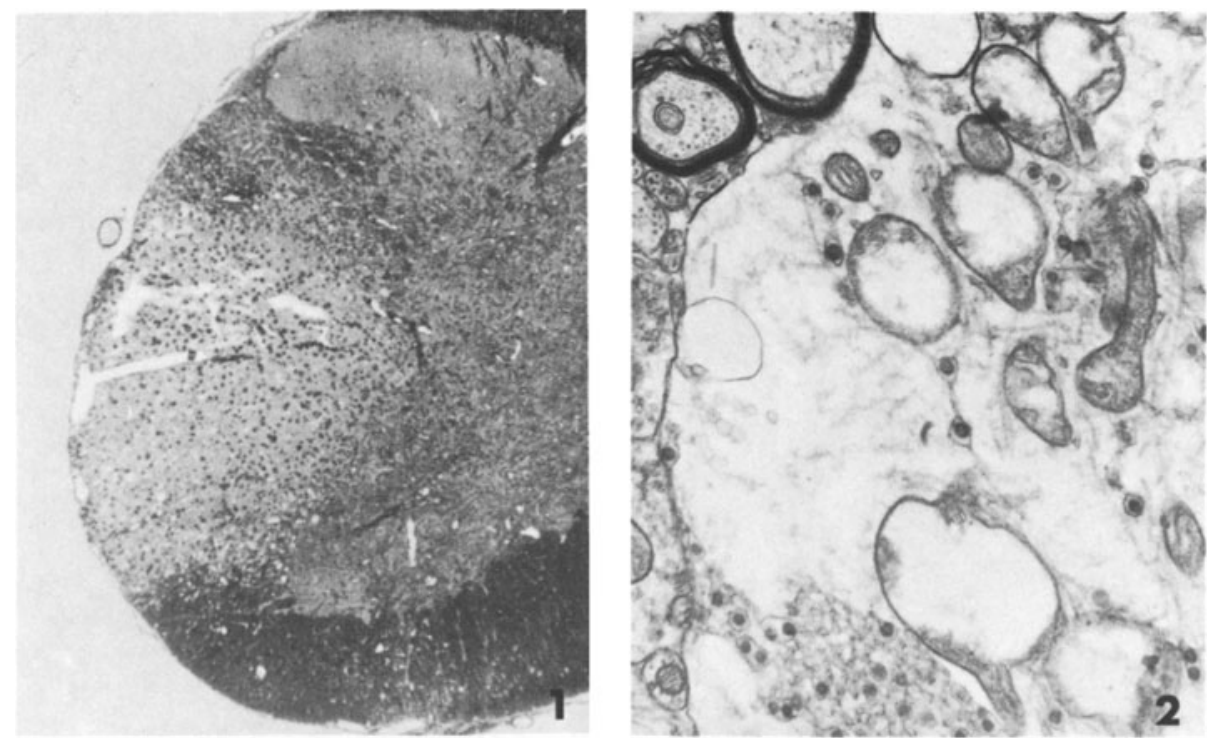

Fig. 1. Demyelinating lesion of the spinal cord from an animal which developed clinical signs 18 days after infection. Widespread lesion in the right lateral funiculus. Dark cells are macrophages loaded with lipid material. Note the spongy state in the anterior funiculus. Toluidine blue staining. $x 40$

Fig. 2. Part of the hypertrophically degenerating cell found in a pontine spongy state of an animal with subacute onset. Intact virus particles are visible in vesicles or tubulovesicular structures. Note the increased amount of microtubules in this degenerating cytoplasma. x 25,000

nerve, and the spinal cord (Fig. 1). The lesions consisted of widespread loss of myelin sheaths with preservation of axons and neurons, presenting a primary demyelination [8]. Lymphoid cells, plasma cells, and monocytes were found scattered in the lesions and massively around blood vessels inside or near demyelinated foci. Neither neuronal necrosis, nor giant cell formation, nor inclusion bodies were observed. Immunofluorescent studies showed that viral antigen was confined to glial cells. Neurons were always unstained, even in areas where the lesions involved the pontine nucleus. Despite the large amount of viral antigen, intact virus particles were rarely observed. They were only detectable in hypertrophically degenerated cells (Fig. 2). These degenerating cells were encountered in the spongy state of the white matter. A morphological investigation of the initial demyelinating lesions suggested that the hypertrophically degenerating cells might originate from both astrocytes and large oligodendrocytes [8]. Infectious virus could be isolated from all diseased rats.

\section{Demyelinating Disease with a Long Incubation Period}

3 animals developed clinical signs 3, 6, and 8 months after inoculation [9]. In these animals the predominant neuropathological finding consisted of primary demyeli- 


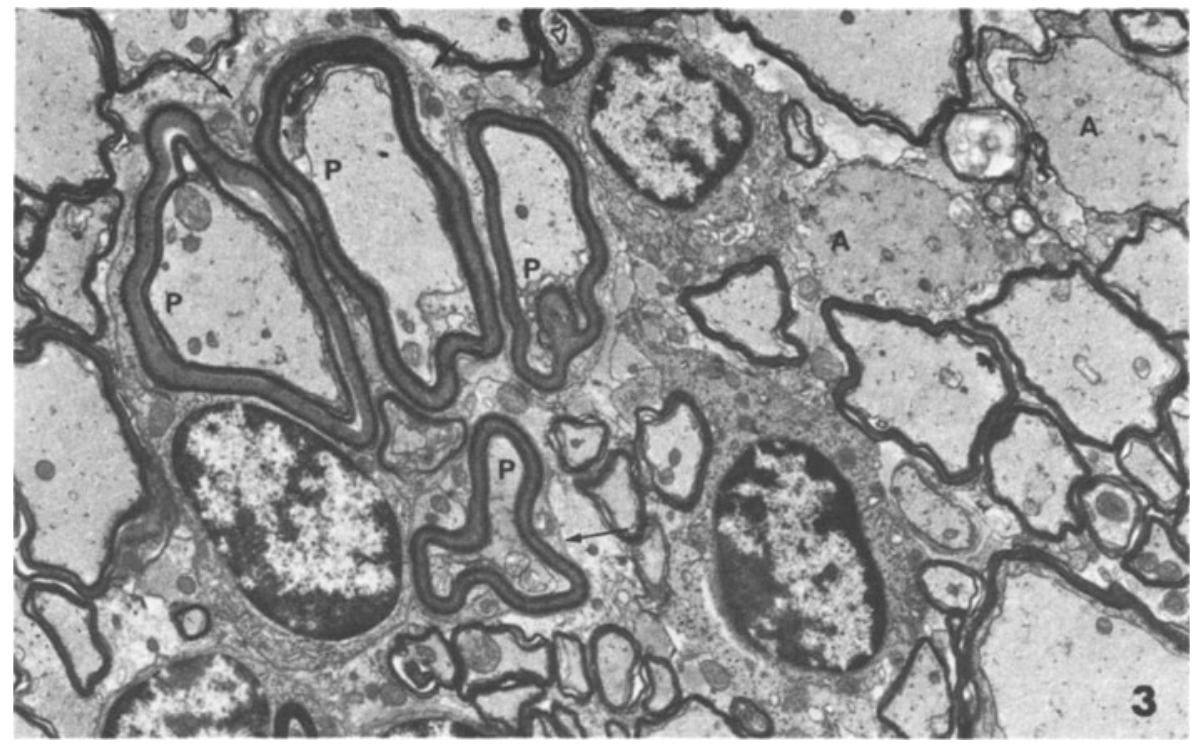

Fig. 3. Small-cell focus found in an animal which developed clinical signs 8 months after infection. Two naked axons $(A)$ are seen. Well-developed myelin sheaths $(P)$ are surrounded by the basement membrane $\rightarrow$ ). These myelin sheaths correspond to the PNS-type of remyelination. Myelin sheaths without the basement membrane are thin, compared to the diameter of axons. These myelin sheaths correspond to CNS-type of remyelination. x 20,000

nation with a mononuclear inflammatory cell response. Demyelinating plaques were usually large and distributed both in the deep cerebral white matter, the brainstem, and the spinal cord. Neurons and axons were well preserved within the lesions, which were morphologically similar to those of SDE.

In the animal which developed clinical signs 8 months after inoculation, foci consisting of an aggregation of small cells and intact myelin sheaths were found in the white matter of the pons, and spinal cord. Electron-microscopic examination of these foci revealed numerous thinly myelinated axons and small aggregated cells. Naked axons and incompletely myelinated axons were also observed (Fig. 3). Moreover, the well-developed myelin sheaths were surrounded by a basement membrane. These morphologically distinct features of myelin sheaths are similar to those observed during remyelination [2,3]. Myelin sheaths surrounded by the basement membrane correspond to the PNS type of remyelination and those without basement membrane to the CNS type of remyelination. The observation of both demyelination and remyelination in this animal suggests a recurrent disease process.

Infectious virus was isolated from the cace with a 3-month incubation period. Viral antigen was detected by immunofluorescence only in glial cells of the white matter of the pons, and spinal cord. The other two animals were sacrificed by perfusion for ultrastructural studies. Virus particles could not be detected by electron microscopy in these cases. However, it is conceivable that the selected areas were not focussed to the sites of virus replication. 


\section{Animals Without Recognizable Clinical Signs}

In animals which did not display clinical signs, no active lesions were found. However, in 10 rats out of 24 examined, small-cell foci, and in two additional animals, a slight hydrocephalus was observed. The small-cell foci were similar to those found in the diseased animals with long incubation periods. They were found in the cerebral crus, pons, cerebellar peduncles, and spinal cord. Electron microscopic study of the small-cell foci revealed a state of PNS- and CNS-type remyelination (Table 2). Infectious virus could not be isolated.

Table 2. Summary of the main neuropathological findings of JHM infection in weanling rats

\begin{tabular}{|c|c|c|c|c|c|c|}
\hline \multirow{2}{*}{$\begin{array}{l}\text { Number } \\
\text { of animals }\end{array}$} & \multirow{2}{*}{$\begin{array}{l}\text { Neurological } \\
\text { disease with } \\
\text { clinical signs }\end{array}$} & \multirow{2}{*}{$\begin{array}{l}\text { Incubation } \\
\text { Period }\end{array}$} & \multicolumn{2}{|l|}{ Inflammation } & \multirow{2}{*}{$\begin{array}{l}\text { Demyeli- } \\
\text { nation }\end{array}$} & \multirow{2}{*}{$\begin{array}{l}\text { Remyeli- } \\
\text { nation }\end{array}$} \\
\hline & & & $\begin{array}{l}\text { Perivascular } \\
\text { Cuffing }\end{array}$ & Diffuse & & \\
\hline 33 & + & $2-3$ weeks & + & + & + & - \\
\hline 1 & + & 3 months & + & $(+)$ & + & - \\
\hline 1 & + & 6 months & + & $(+)$ & + & - \\
\hline 1 & + & 8 months & + & $(+)$ & + & + \\
\hline 10 & - & $6-8$ months & - & - & - & + \\
\hline
\end{tabular}

\section{Comments}

Intracerebral inoculation of JHM virus in rats leads to different CNS disorders, depending on the age of the animals at the time of infection. Acute encephalomyelitis occurs in suckling rats and infects both neurons and glia cells. The infection spreads so rapidly that the animals die within 24 to $48 \mathrm{~h}$ after infection which is clinically of an acute nature. The disease in weanling rats, however, is different from the acute case. Small and large sharply demarcated demyelinating lesions are located in the deep cerebral white matter, optic chiasma, pons, and spinal cord, accompanied by perivascular infiltrations consisting of plasma cells and monocytes. Virus particles and antigen can only be detected in glia cells and not in neurons, suggesting a selective vulnerability of glia cells for JHM virus at this age of the animals.

In addition to these diseases, a more chronic CNS infection can develop in rats months after JHM inoculation. The neuropathological findings are similar to those observed in SDE, except for the occurrence of remyelination which consists of the PNS and CNS type. It is noteworthy that infectious virus can be isolated from these animals, suggesting a state of virus persistency. Remyelination of both PNS and CNS type first appears in rats at least 2-3 months after demyelination [3]. Therefore, the finding of this type of remyelination in clinically silent animals suggests that these animals had a subclinical demyelinating disease some months prior to investigation. In other experiments, weanling rats infected with JHM virus developed, after 6 to 8 months, a chronic progressive paralysis characterized by hydrocephalus and myelomalacia $[7,8]$. In these cases no direct evidence for a participation of 
JHM virus in this disease was found. The neuropathology of this progressive paralysis differed completely from the late demyelinating disease.

At present it is not known which mechanisms are responsible for the different CNS diseases observed. It has been shown that susceptibility of mice for a mouse hepatitis virus infection depends not only on a genetic predisposition, but also on factors such as age $[10,11,13]$. On the other hand, properties of a virus preparation may also play a role, since certain temperature-sensitive mutants of JHM virus are inducing a more pronounced demyelinating disease than the wild type virus [4].

Further studies combining virological, immunological, and biochemical analysis of JHM infection in vitro and in vivo should lead to a better understanding of the virus-cell and virus-host interaction in a demyelinating disease.

Acknowledgments. This work was supported by the Deutsche Forschungsgemeinschaft, Schwerpunkt "Multiple Sklerose und verwandte Erkrankungen”, Az 270/16.

\section{References}

1. Bailey OT, Pappenheimer AM, Cheever FS, Daniels JB (1949) A murine virus (JHM) causing disseminated encephalomyelitis with extensive destruction of myelin. II. Pathology. J Exp Med 90:195-212

2. Blakemore WF (1974) Pattern of remyelination in the CNS. Nature 249:575-578

3. Blakemore WF (1975) Remyelination by Schwann cells of axons demyelinated by intraspinal injection of 6-aminonicotinamide in the rat. J Neurocytol 4:745-757

4. Haspel VM, Lampert PW, Oldstone MBA (1978) Temperature-sensitive mutants of mouse hepatitis virus produce a high incidence of demyelination. Proc Natl Acad Sci USA 75:4033-4036

5. Lampert PW, Sims JK, Kniazeff AJ (1973) Mechanism of demyelination in JHM virus encephalomyelitis. Electron microscopic studies. Acta Neuropathol. (Berl.) 24, 76-85

6. Lucas A, Coulter M, Anderson R, Dales S, Flintoff W (1978) In vivo and in vitro models of demyelinating diseases II. Persistence and host-regulated thermosensitivity in cells of neuronal derivation infected with mouse hepatitis and measles viruses. Virology 88:325-337

7. Nagashima K, Wege H, ter Meulen V (1978) Early and late CNS-effects of coronavirus infection in rats. Adv Exp Med Biol 100:395-409

8. Nagashima K, Wege H, Meyermann R, ter Meulen V (1978) Coronavirus induced subacute demyelinating encephalomyelitis in rats. A morphological analysis. Acta Neuropathol (Berl) 44:63-70

9. Nagashima K, Wege H, Meyermann R, ter Meulen V (1979) Demyelinating Encephalomyelitis induced by a long-term coronavirus infection in rats. Acta Neuropathol (Berl) 45:205-213

10. Stohlman SA, Weiner LP (1978) Stability of neurotropic mouse hepatitis virus (JHM strain) during chronic infection of neuroblastoma cell. Arch Virol 57:53-61

11. Stohlman SA, Frelinger JA (1978) Resistance to fatal central nervous system disease by mouse hepatitis virus, strain JHM. I. Genetic analysis. Immunogenetics 6:277-282

12. ter Meulen V, Wege H (1978) Virus infection in demyelinating diseases. Adv Exp Med Biol 100:383-394

13. Virelizier JL, Dayan AD, Allison AC (1975) Neuropathological effects of persistent infection of mice by mouse hepatitis virus. Infect Immun 12:1127-1140

14. Wege H, Müller A, ter Meulen V (1978) Genomic RNA of the murine coronavirus JHM. J Gen Virol 41:217-227

15. Wege H, Wege H, Nagashima K, ter Meulen V (1979) Structural Polypeptides of the murine coronavirus JHM. J Gen Virol 42:37-47

16. Weiner, LP (1973) Pathogenesis of demyelination induced by a mouse hepatitis virus (JHM virus). Arch Neurol 28:293-303 